\title{
HOÀN CẢNH GIA ĐİNH VỚI SỬ THÍCH ÚNG CỦA TRẺ 5-6 TUỔI TRONG CÁC HOẠT ĐộNG CHUẨN BỊ ĐẾN TRƯờnG PHỔ THÔNG
}

\section{Family situation and adaption of of 5-6 year old children in preparing activities for going to Primary school}

ThS. Vũ Thị Kiều Trang*

\section{TÓM TẮT}

Có nhiều yếu tố khác nhau ảnh hưởng đến sự thích ứng của trẻ 5-6 tuổi trong các hoạt động chuẩn bị đến trường phổ thông, trong đó hoàn cảnh gia đình là yếu tố có ảnh hưởng lớn nhất. Khi xem xét các nội dung ảnh hưởng của yếu tố này, có thể nhận thấy, những hoạt động chung và sự quan tâm của cha mẹ với con có ảnh hưởng nhiều nhất; bầu không khí và quan hệ gia đình ở vị trí thứ hai; mức thu nhập của gia đình ở vị trí thứ ba. Ngoài ra, nhận thức của cha mẹ về mức độ cần thiết của việc chuẩn bị cho trẻ đến trường phổ thông cũng có tác động không nhỏ đến sự thích ứng của trẻ. Mỗi nội dung, tuy có sự ảnh hưởng khác nhau, nhưng đều có mối liên hệ mật thiết với nhau trong việc tác động đến sự thích ứng của trẻ 5-6 tuổi.

Tù khoá:hoàn cảnh gia đình, thích ứng, hoạt động, chuẩn bị, truờng phổ thông.

\begin{abstract}
Family situation is the most important factor in various factors affecting the preparing activities for going to Primary school. There are so many elements in family situation, the first importance is the common activities and parent concerns for their children, the second are family environment and relationships, the last one is family income. In addition, parents have to understand that preparing activities for going to Primary school affect so much the adaptive behaviour of children. These elements play different roles but have a reciprocal relation affecting the adaptive behaviours of 5-6 years old children.
\end{abstract}

Key words: family situation, adaptation, activity, prepare, primary school

\section{1. Đặt vấn đề}

Để tồn tại và phát triển trong cuộc sống xã hội đang vận động không ngừng như hiện nay, mỗi con người phải có sự thích ứng tốt. Sự thích ứng là một trong những điều kiện để con người tham gia vào đời sống xã hội đầy biến động một cách có hiệu quả nhất.

Trẻ em nói chung và trẻ 5 - 6 tuổi nói riêng còn non nớt về thể chất, yếu đuối về tinh thần và dễ dàng gặp phải những khó khăn, trở ngại, những nguy hiểm trong cuộc sống. Do đó, giúp trẻ có được sự thích ứng để vượt qua những khó khăn, trở ngại là điều vô cùng quan trọng.

Trẻ 5-6 tuổi tiến vào bước ngoặt quan trọng của cuộc đời, đó là việc chuyển từ bậc học mầm non sang bậc học phổ thông. Việc chuẩn bị cho trẻ 5-6 tuổi đến trường phổ thông cần thực hiện đầy đủ các nội dung phù hợp với chương trình giáo dục mầm non và đề án Phổ cập giáo dục mầm non cho trẻ em 5 tuổi giai đoạn 2010-2015 do Bộ Giáo dục và Đào tạo đã đề ra. Các nội dung được xây dựng dựa trên 4 lĩnh vực chủ yếu gồm:

\footnotetext{
* Trường Đại học Tân Trào
} 
- Hoạt động phát triển thể chất: Bao gồm các hoạt động giáo dục phát triển vận động như: khả năng thực hiện vận động thô, vận động tinh trong sinh hoạt hàng ngày. Hoạt động giáo dục dinh dưỡng sức khỏe như: cung cấp những kiến thức, kỹ năng nhằm hình thành thói quen, hành vi có lợi cho sức khỏe;

- Hoạt động phát triển nhận thức: Bao gồm hoạt động khám phá khoa học, hoạt động làmquen với toán, hoạt động âm nhạc và tạo hình, hoạt động khám phá môi trường xã hội;

- Hoạt động phát triển ngôn ngũu: Bao gồm hoạt động phát triển khả năng nghe và nói; hoạt động kể chuyện, đọc thơ, đồng dao, ca dao, tục ngữ; trò chơi đóng kịch; kể chuyện sáng tạo; chuẩn bị cho việc học đọc, học viết;

- Hoạt động phát triển tình cảm và quan hệ xã họi: Bao gồm các hoạt động phát triển tình cảm: giáo dục ý thức về bản thân; giáo dục trẻ nhận biết và thể hiện cảm xúc, tình cảm với con người, sự vật và hiện tượng xung quanh; phát triển kỹ năng xã hội:giáo dục các hành vi và quy tắc ứng xử xã hội; giáo dục bảo vệ môi trường.

Giúp trẻ có được một tâm thế sẵn sàng, một hành trang đầy đủ về mặt kiến thức để có thể thích ứng nhanh nhất với hành trình mới này cần đến sự chuẩn bị công phu, tỷ mỷ của người lớn.

Tuy nhiên, trong quá trình trẻ tham gia các hoạt động chuẩn bị đến trường phổ thông cũng có những yếu tố chủ quan, khách quan khác nhau ảnh hưởng đến sự thích ứng của trẻ. Việc xác định được những yếu tố ảnh hưởng đến sự thích ứng của trẻ 5-6 tuổi trong các hoạt động chuẩn bị đến trường phổ thông là việc làm cần thiết. Việc làm này giúp các nhà giáo dục và các bậc cha mẹ trẻ có những biện pháp tác động phù hợp và hiệu quả hơn nhằm nâng cao mức độ thích ứng cho trẻ 5-6 tuổi trong hoạt động chuẩn bị đến trường phổ thông. Một trong những yếu tố có sức ảnh hưởng lớn đến sự phát triển tâm lý nói chung và sự thích ứng của trẻ nói riêng đó là hoàn cảnh gia đình

Gia đình là môi trường sống, môi trường văn hoá đầu tiên của mỗi con người. Với phương thức chăm sóc bằng tình thương yêu ruột thịt, bằng cách giao tiếp trực tiếp và thường xuyên, gia đình có ảnh hưởng tuyệt đối đến quá trình phát triển của con người. Vấn đề cốt lõi trong mỗi gia đình là mối quan hệ của cha mẹ và con cái. Theo Jonh Bowlby, mối quan hệ giữa cha mẹ và con cái có các mức độ tương tác khác nhau. Mối quan hệ này ảnh hưởng đến quá trình xã hội hoá trẻ em. Ainsworth (1973) cũng cho rằng, vai trò của cha mẹ trong gia đình như một "cơ sở an toàn" để trẻ tiến hành thăm dò thế giới [4;tr78].

\section{Khách thể và phương pháp nghiên cứu}

Nghiên cứu trên 280 khách thể gồm: 110 trẻ mẫu giáo 5-6 tuổi, 110 cha (mẹ) trẻ, 40 giáo viên mầm non và 20 chuyên gia trong lĩnh vực giáo dục mầm non thuộc 4 trường mầm non trên địa bàn tỉnh Tuyên Quang (Trường mầm non Phúc Thịnh và mầm non Ngọc Hội huyện Chiêm Hoá - Tuyên Quang; Trường mầm non Hoa Sen và mầm non $\mathrm{SaO}$ Mai - Thành phố Tuyên Quang)

Phương pháp chính được sử dụng trong nghiên cứu này là phương pháp điều tra bằng bảng hỏi. Bảng hỏi được thiết kế với chủ yếu các câu hỏi có sẵn phương án trả lời, thang đánh giá có 4 mức độ (từ $1-4$ điểm). Phần mềm SPSS 16.0 được sử dụng để xử lý kết quả nghiên cứu. Ngoài ra chúng tôi kết hợp sử dụng phương pháp nghiên cứu tài liệu, phương pháp quan sát, phỏng vấn sâu.

\section{Kết quả nghiên cứu}

Bao giờ cũng vậy, khi nói đến những yếu tố có ảnh hưởng đến sự phát triển của con 
người, điều đầu tiên được đề cập đến sẽ là yếu tố gia đình. Gia đình là nơi nuôi dưỡng, giáo dục và có ảnh hưởng lớn đến mỗi cá nhân từ khi sinh ra và cả quá trình trưởng thành sau này.

Sống trong gia đình, đứa trẻ hình thành mối gắn bó tình cảm với những người ruột thịt; vì vậy, mọi sự chia tách tình cảm gia đình, sự thiếu vắng cha mẹ hay những điều kiện bất lợi về các mối quan hệ gia đình đều có những ảnh hưởng nhất định đến sự thích ứng của trẻ với hoàn cảnh sống. James Chapman trích trong tờ báo Anh "Thu tín hàng ngày" (18/4/2011): Theo Nghiên cứu của Trung tâm công bằng xã hội cứ "một đứa trẻ lớn lên trong gia đình chỉ có cha hoặc mẹ thường có hơn $75 \%$ khả năng thất bại trong học tập ở trường, 70\% khả năng rơi vào nghiệm ma tuý, hơn $50 \%$ có vấn đề về rượu và 35\% sẽ thất nghiệp khi lớn lên" [1;tr172].

Do đó, khi đề cập đến ảnh hưởng của hoàn cảnh gia đình đối với sự thích ứng của trẻ trong các hoạt động chuẩn bị đến trường phổ thông, chúng tôi tìm hiểu các khía cạnh bao gồm: mức thu nhập của gia đình, bầu không khí và quan hệ gia đình, các hoạt động chung và sự quan tâm giữa cha mẹ với con cái trong gia đình và nhận thức của cha mẹ trẻ về sự cần thiết của việc chuẩn bị cho trẻ đến trường phổ thông.

\begin{tabular}{|c|c|c|c|}
\hline $\begin{array}{c}\text { Các nội dung ảnh } \\
\text { hưởng }\end{array}$ & ĐТВ & ĐLC & $\begin{array}{l}\text { Thứ } \\
\text { bậc }\end{array}$ \\
\hline $\begin{array}{l}\text { 1. Mức thu nhập của gia } \\
\text { đình }\end{array}$ & 1.79 & 0.40 & 3 \\
\hline $\begin{array}{l}\text { 2. Bầu không khí và } \\
\text { quan hệ gia đình }\end{array}$ & 2.75 & 0.45 & 2 \\
\hline $\begin{array}{l}\text { 3. Các hoạt động chung } \\
\text { và sự quan tâm của cha } \\
\text { mẹ với con }\end{array}$ & 2.99 & 0.09 & 1 \\
\hline
\end{tabular}

Bảng 1. Các nội dung ảnh hwởng của hoàn cảnh gia đình đến sư thích úng của trẻ trong hoạt động chuẩn bị đến trường phổ thông

Bảng trên cho thấy những tác động từ gia đình đến sự thích ứng của trẻ, trong đó các hoạt động chung, sụ quan tâm của cha mẹ với con có ảnh hưởng lớn nhất và xếp vị trí đầu tiên (ĐTB: 2.99; ĐLC: 0.09).

Kết quả nghiên cứu phản ánh đúng thực tiễn và phù hợp với những gì chúng tôi tìm hiểu, quan sát được ở gia đình của trẻ. Gia đình thường xuyên có những hoạt động cùng nhau giữa các thành viên như: trò chuyện, giao lưu, trao đổi, cùng chơi, cùng ăn uống, cùng nghỉ ngơi... giữa bố - mẹ, bố mẹ - con cái sẽ có ảnh hưởng tích cực đến trẻ, kích thích việc phát triển ngôn ngữ cho trẻ. Thông qua các hoạt động chung với gia đình, trẻ thoải mái trò chuyện, bộc bạch suy nghĩ, hiểu biết của mình, trẻ học cách thể hiện xúc cảm, tình cảm của mình bằng ngôn ngữ; từ đó, hình thành trong tư duy của trẻ thái độ coi trọng ngôn ngữ - "nguyên liệu" nuôi dưỡng thói quen đọc sách sau này của trẻ.

Bên cạnh đó, khi trẻ luôn nhận được sự quan tâm chăm sóc đúng mức, kịp thời của cha mẹ về vật chất và tinh thần trẻ sẽ thấy tự tin hơn trong những tình huống, những mối quan hệ, giao tiếp xã hội. Trẻ thực sự nhanh chóng hòa nhập với môi trường mới tốt hơn so với trẻ không nhận được sự quan tâm từ bố mẹ. Trước môi trường hoạt động mới, trẻ luôn có được cảm giác an toàn, giúp trẻ yên tâm, vui vẻ hồn nhiên, mạnh dạn thăm dò, thử nghiệm, tìm cách tác động lên sự vật hiện tượng, phát huy được tiềm năng cả về thể chất và tâm lý.

Trái lại, nếu trẻ phải sống trong gia đình thiếu sự quan tâm chăm sóc về vật chất hoặc tinh thần từ cha mẹ hay người thân, trẻ không có cơ hội được cùng cha mẹ và các thành viên 
khác tham gia những hoạt động chung với nhau sẽ là một thiệt thòi lớn đối với trẻ. Trong những hoàn cảnh này trẻ thường tự ti, mặc cảm, ngại giao tiếp, sống khép mình nên khó khăn trong việc thích ứng với những môi trường sống mới. Quan sát thực tế giờ đón trẻ ở trường mầm non chúng tôi nhận thấy, trẻ rất hào hứng khi có người nhà đến đón. Trẻ sẽ tự tin trao đổi về những hoạt động được trong ngày ở lớp nếu cha, mẹ hoặc người thân cởi mở trò chuyện, khen ngợi, đặc biệt là động viên "thành tích" mà trẻ đạt được ở lớp.

Sự thường xuyên quan tâm đến nhau của các thành viên trong gia đình sẽ là những điều kiện thuận lợi để các thành viên hỗ trợ, chia sẻ, động viên, khuyến khích và dành những điều tốt nhất cho nhau. Người lớn trong gia đình dạy trẻ bằng giao tiếp trực tiếp và thường xuyên ở mọi lúc, mọi nơi, trong các tình huống của cuộc sống thực xung quanh.Đứa trẻ học ăn, học nói, học gói, học mở, học làm người một cách tự nhiên và nhẹ nhàng [8;tr62]. Do đó, sống trong một môi trường gia đình hạnh phúc, trẻ em sẽ nhận được đầy đủ sự quan tâm của cha mẹ, sẽ được nâng đỡ, được tham gia nhiều hơn mỗi khi trẻ có nhu cầu hoạt động. Gia đình là môi trường trẻ được chăm sóc, nuôi dạy an toàn và thoả mãn được các nhu cầu của trẻ, thúc đẩy sự phát triển toàn diện của trẻ.

Vị trí ảnh hưởng thứ hai trong những tác động từ hoàn cảnh gia đình đến sự thích ứng của trẻ là bầu không khí và quan hệ gia đình (ĐTB:2.75; ĐLC: 0.45).

Tổ ấm gia đình là một môi trường văn hoá được tạo nên trên cơ sở tình thương yêu, đùm bọc lẫn nhau của những người ruột thịt trong gia đình - gọi là văn hoá gia đình [8;tr61]. Bầu không khí tâm lý tích cực, thoải mái, vui vẻ được tạo dựng trên cơ sở tình yêu thương, đùm bọc lẫn nhau của những người ruột thịt, điều này có ảnh hưởng đến mọi thành viên trong gia đình, trong đó có trẻ em. Nếu trẻ may mắn được sinh ra và lớn lên trong một gia đình tốt, nề nếp, nhân văn, được giáo dục đầy đủ, đúng đắn thì trẻ thường chủ động, tích cực, tự tin, dễ làm chủ trong mọi tình huống. Đặc biệt sẽ có tác động rất tích cực đến sự phát triển tình cảm và các mối quan hệ xã hội của trẻ. Trong gia đình luôn có sự yêu thương, tôn trọng, có sự liên kết gắn bó giữa các thành viên sẽ là chỗ dựa tinh thần rất lớn đối với trẻ. Cùng với sự quan tâm, chăm sóc, nuôi dưỡng chu đáo và sự hướng dẫn, giúp đỡ của cha mẹ sẽ giúp trẻ khám phá thế giới xung quanh (cây cối, vật nuôi, các hiện tượng thiên nhiên) nhờ đó mà nhận thức, ngôn ngữ của trẻ ngày càng được phát triển hơn.

Xếp ở vị trí cuối cùng là mức thu nhập của gia đình (ĐTB:1.79; ĐLC: 0.40), thu nhập của gia đình là một yếu tố cần thiết nhưng không hoàn toàn quyết định sự thích ứng của trẻ. Thu nhập phản ánh khả năng kinh tế của gia đình trong việc đầu tư cho con học tập. Nếu gia đình nào có thu nhập cao sẽ có thể có điều kiện mua sắm, trang bị cho con những đồ dùng học tập, cho trẻ đi tham quan, học tập ở nhiều môi trường khác nhau. Tuy nhiên, đối với trẻ mầm non những chi phí cho học tập của trẻ là không đáng kể so với học sinh các bậc học phổ thông. Do đó, mức thu nhập của gia đình chỉ có thể ảnh hưởng phần nào đến sự thích ứng của trẻ. Nếu trẻ có được một gia đình có sự quan tâm, bầu không khí tâm lý vui vẻ, tích cực sẽ giúp trẻ tự tin và chủ động, tích cực hòa nhập hơn trong môi trường xã hội và các hoạt động học tập trên lớp. Điều này được minh chứng bằng những trường hợp cụ thể mà chúng tôi tìm hiểu được. Có gia đình, điều kiện kinh tế rất khá giả, trẻ được đáp ứng đầy đủ các điều kiện vật chất, nhưng mối quan hệ của các thành viên 
trong gia đình không gắn bó, thiếu sự quan tâm, chia sẻ, giúp đỡ lẫn nhau thì trẻ em sống trong gia đình đó cũng không tự tin, khó hoà nhập và thường xa lánh mọi người

Để làm rõ hơn về vai trò của hoàn cảnh gia đình với sự thích ứng của trẻ 5-6 tuổi trong các hoạt động chuẩn bị đến trường phổ thông, chúng tôi đã tìm hiểu nhận thức của cha, mẹ trẻ về mức độ cần thiết của việc chuẩn bị cho trẻ đến trường phổ thông. Kết quả được thống kê ở bảng dưới đây:

\begin{tabular}{|l|c|c|c|}
\hline $\begin{array}{l}\text { Nội dung chuẩn } \\
\text { bị cho trẻ 5-6 } \\
\text { tuổi } \\
\text { đến trường phổ } \\
\text { thông }\end{array}$ & $\begin{array}{c}\mid 3 \\
\text { Kần thiết } \\
(\%)\end{array}$ & $\begin{array}{c}\text { Cần độn } \\
\text { thiết } \\
(\%)\end{array}$ & $\begin{array}{c}\text { Rất } \\
\text { cần } \\
\text { thiết } \\
(\%)\end{array}$ \\
\hline $\begin{array}{l}\text { 1. Chuẩn bị về } \\
\text { thể chất }\end{array}$ & 0.9 & 16.7 & 82.4 \\
\hline $\begin{array}{l}\text { 2. Chuẩn bị về } \\
\text { nhận thức }\end{array}$ & 0 & 9.3 & 90.7 \\
\hline $\begin{array}{l}\text { 3. Chuẩn bị về } \\
\text { ngôn ngữ, giao } \\
\text { tiếp }\end{array}$ & 0.9 & 15.7 & 83.3 \\
\hline $\begin{array}{l}\text { 4. Chuẩn bị về } \\
\text { tình cảm, kỹ } \\
\text { năng xã hội }\end{array}$ & 3.7 & 18.5 & 77.8 \\
\hline
\end{tabular}

Bảng 2. Mức độ cần thiết của các nội dung chuẩn bị cho trẻ 5-6 tuổi đến trường phổ

thông

Nhìn vào bảng 2 , kết quả điều tra cho thấy, đối với nội dung chuẩn bị thể chất cho trẻ đến trường phần lớn phụ huynh cho rằng là rất cần thiết $(82.4 \%)$, có $(16.7 \%)$ số người được hỏi trả lời cần thiết. Như vậy, cho dù ở hoàn cảnh gia đình như thế nào thì các bậc phụ huynh luôn sẵn sàng có thể đóng góp để trẻ có điều kiện học tập tốt nhất, đặc biệtlà sự chăm sóc về sức khỏe và dinh dưỡng cho trẻ. Do điều kiện kinh tế xã hội ngày càng phát triển, nên việc đáp ứng nhu cầu vật chất, đặc biệt là nhu cầu dinh dưỡng cho trẻ em ngày càng được các bậc phụ huynh quan tâm. Đa số các bậc cha mẹ nhìn nhận sự phát triển của con ở mặt thể chất, thấy con cao lớn, mập mạp hơn các bạn là yên tâm, thậm chí có cha mẹ lo lắng quá mức khi con có thể trạng nhỏ hơn các bạn khác, dẫn đến việc ép trẻ ăn uống hoặc sử dụng những sản phẩm kích thích trẻ tăng trưởng về thể chất. Do đó,chỉ có $(0.9 \%)$ phụ huynh cho rằng điều đó là không cần thiết, tỷ lệ thấp hơn so với các mức độ khác.

Ở lĩnh vực chuẩn bị về mặt nhận thức, có $100 \%$ phụ huynh học sinh trả lời là cần thiết và rất cần thiết, trong đó có tới $90,7 \%$ các bậc cha mẹ cho rằng điều này rất cần thiết. Như vậy, sự quan tâm của gia đình đối với sự phát triển nhận thức cho trẻ là rất lớn. Hầu như tất cả phụ huynh đều mong muốn con cái của mình thông minh, học giỏi. Nhu cầu này là tất yếu, cũng chính là động lực khiến cho cha mẹ có thể chấp nhận đương đầu với khó khăn, thiệt thòi và hy sinh để con cái được học hành đến nơi đến chốn. Đây cũng là nguyên nhân dẫn đến thực trạng đáng ngại trong thời gian gần đây trong việc chuẩn bị cho trẻ đến trường phổ thông, đó là cho trẻ học trước chương trình lớp một; dạy trẻ tập viết, ghép vần, dạy các phép tính... để mong trẻ đọc thông, viết thạo trước khi đi học.

Đối với sự cần thiết quan tâm đến việc phát triển ngôn ngữ và giao tiếp cho trẻ, phần lớn phụ huynh $(83,3 \%)$ đánh giá là rất cần thiết đối với sự chuẩn bị cho trẻ đến trường phổ thông. Chỉ có $0.9 \%$ số phụ huynh được hỏi cho rằng sự chuẩn bị là không cần thiết. Thực tế này phản ánh, phụ huynh có nhận thức rất tốt trong các vấn đề chuẩn bị, chăm lo cho con đến trường. Điều này cũng phản ánh thực tế là hầu hết các bậc cha mẹ trẻ đều hiểu rõ về tầm quan trọng của ngôn ngữ và giao tiếp đến khả năng thành công của mỗi con người. Do đó, phụ huynh cũng luôn kỳ vọng và mong muốn con em mình phải có khả năng về ngôn ngữ tốt, giao tiếp tự tin để mở rộng các quan hệ xã hội mà trẻ có thể tham gia. 
Cha mẹ luôn chú ý nhắc nhở, hướng dẫn trẻ bắt chước hành vi giao tiếp, ứng xử tốt của những người xung quanh.

So với các nội dung trên thì việc phát triển tình cảm và quan hệ xã hội cho trẻ chỉ có $77,8 \%$ phụ huynh được hỏi đánh giá rất cần thiết (thấp nhất trong các nội dung được hỏi ở mức độ này). Từ số liệu này cho thấy, nếu những nội dung phát triển thể chất, nhận thức, ngôn ngữ và giao tiếp được các bậc phụ huynh đánh giá cao hơn vì đó là những nội dung mà trẻ có thể có những biểu hiện cụ thể, rõ ràng mà cha mẹ có thể nhìn thấy ngay được, ví dụ: trẻ tăng cân, khoẻ mạnh; trẻ biết chữ, biết số; trẻ mạnh dạn giao tiếp. Nhưng sự phát triển tình cảm và quan hệ xã hội ở trẻ có phần "thầm lặng" hơn khiến nhiều bậc cha mẹ bỏ qua, không để ý tới. Đặc biệt là các biểu hiện xúc cảm, tình cảm của trẻ thường có một sốphụ huynh chưa quan tâm và có thể cho rằng cảm xúc của trẻ conkhông quan trọng. Mặc dù không có quá nhiều bậc phụ huynh đánh giá sự phát triển tình cảm và quan hệ xã hội là không cần thiết, nhưng tỷ lệ đánh giá nội dung này ở mức độ rất cần thiết ít hơn so với các nội dung khác cũng thể hiện quan điểm, nhận thức của một số cha mẹ trẻ chưa đúng đắn về ý nghĩa của xúc cảm, tình cảm và các mối quan hệ xã hội đối với sự thích ứng của trẻ. Sự phát triển cảm xúc của trẻ có sự chi phối mạnh mẽ đến kết quả phát triển thể chất, nhận thức hay ngôn ngữ và giao tiếp, trẻ chỉ thực sự có thể dễ dàng tiếp thu kiến thức, tự tin giao tiếp... khi trẻ có một tâm trạng tốt, xúc cảm tích cực.

Gia đình là môi trường giáo dục đặc biệt đối với trẻ em, đây là môi trường an toàn, phong phú, trong đó trẻ được nuôi dạy theo một phương thức đặc biệt - phương thức gia đình (khác với phương thức nhà trường) [8;tr61]. Ở trong gia đình, cha mẹ và những người thân là người thầy đầu tiên của trẻ. Cha mẹ dạy trẻ biết lễ phép với mọi người trong giao tiếp dần dần trẻ học cách ứng xử phù hợp, biết kiềm chế hành vi, xúc cảm theo chuẩn mực xã hội. Đặc biệt đối với trẻ 5-6 tuổi, thông qua sự chuẩn bị kĩ càng các điều kiện phát triển cho trẻ, trẻ sẽ học hỏi, tiếp nhận được các giá trị sống tốt đẹp, hình thành nên những kĩ năng sống tích cực, có tâm thế tự tin, vui vẻ thoải mái và dễ dàng thích ứng với những hoạt động mới hoặc những điều kiện mới trong các hoạt động khi học tập ở trường phổ thông.

\section{Kết luận}

Thích ứng của trẻ 5-6 tuổi trong các hoạt động chuẩn bị cho trẻ đến trường phổ thông là sự thay đổi của trẻ 5-6 tuổi về nhận thức, hành vi, thái độ nhằm vượt qua những trở ngại, khó khăn trong hoạt động vui chơi, học tập, sinh hoạt hàng ngày để hình thành và phát triển các phẩm chất tâm lý cần thiết của một người học sinh trong tương lai. Có nhiều yếu tố khác nhau ảnh hưởng đến sự thích ứng của trẻ 5-6 tuổi trong các hoạt động chuẩn bị đến trường phổ thông, trong đó hoàn cảnh gia đình là yếu tố có sức ảnh hưởng lớn nhất, có tác động mạnh nhất

Trên cơ sở phân tích nội dung ảnh hưởng của hoàn cảnh gia đình đến sự thích ứng của trẻ 5-6 tuổi trong các hoạt động chuẩn bị đến trường phổ thông, chúng tôi có cơ sở đưa ra một số biện pháp tác động và kiến nghị nhằm giúp trẻ dễ dàng có được sự thích ứng, đồng thời góp phần nâng cao hơn nữa chất lượng nguồn lực con người trong tương lai và giúp các bậc phụ huynh có cách nhìn nhận đúng đắn hơn nữa về việc chuẩn bị cho trẻ bước vào lớp một. 


\section{TÀI LIỆU THAM KHẢO}

1. Collete Gray và Macblain (2014), Các lý thuyết học tập về trẻ em, Hiếu Tân dịch, Nhà xuất bản Hồng Đức, Hà Nội.

2. Vũ Dũng (2012). Thích ứng xã hội của nhóm xã hội yếu thế ở nước ta hiện nay. Nxb Từ điển bách khoa

3. Phạm Thị Đức (1991). Chuẩn bị tâm lý cho trẻ vào lớp 1. Tạp chí nghiên cứu giáo dục, số tháng 12

4. Lê Minh Nguyệt (2012), Sự tuoong tác giũa cha mẹ và con với sự phát triển tâm lý của trẻ em, NXB Đại học Sư phạm, Hà Nội

5. Quyết định 239/QĐ-TTG của Thủ tướng Chính phủ ngày 09/02/2010, Quyết định phê duyệt đề án Phổ cập giáo dục mầm non cho trẻ 5 tuổi giai đoạn 2010-2015

6. Trần Thị Ngọc Trúc (2008). Cần chuẩn bị nhũng gì cho trẻ vào lớp một, Nxb tổng hợp Thành phố Hồ Chí Minh.

7. Nguyễn Ánh Tuyết (1999). Chuẩn bị cho trẻ 5 tuổi vào trường phổ thông, Nxb Giáo dục, Hà Nội.

8. Nguyễn Ánh Tuyết (2014). Tâm lý học trẻ em lứa tuổi mầm non, Nxb Đại học Sư phạm, Hà Nội. 